\title{
A Randomized, Controlled Study on the Safety and Efficacy of Maraviroc and/or Favipiravir vs Currently Used Therapy in Severe COVID-19 Adults. "COMVIVIR" Trial.
}

\section{Adolfo Pérez-García}

Hospital General de México "Dr. Eduardo Liceaga" https://orcid.org/0000-0002-9103-5633

Alma Villalobos-Osnaya

Hospital General de México "Dr. Eduardo Liceaga" https://orcid.org/0000-0002-0854-9407

Maria Luisa Hernández-Medel

Hospital General de México "Dr. Eduardo Liceaga"

Lucia Monserrat Perez-Navarro

Hospital General de México "Dr. Eduardo Liceaga" https://orcid.org/0000-0002-9281-9202

Elba O. Medina-Hernandez

Hospital General de México "Dr. Eduardo Liceaga" https://orcid.org/0000-0002-6202-9939

Diana Sofia Cabrera-Orejuela

Hospital General de México "Dr. Eduardo Liceaga"

Ana Maria Espinoza-Garcia

Hospital General de México "Dr. Eduardo Liceaga" https://orcid.org/0000-0003-3255-4051

Mireya Leon-Hernandez

Hospital General de México "Dr. Eduardo Liceaga"

Arianna Rodriguez-Cal Y Mayor

Hospital General de México "Dr. Eduardo Liceaga" https://orcid.org/0000-0002-4619-2701

Raul Serrano-Loyola

Hospital General de México "Dr. Eduardo Liceaga"

Guadalupe Mercedes Lucia Guerrero-Avendaño

Hospital General de México "Dr. Eduardo Liceaga"

Gustavo Reyes-Teran

Comision Coordinadora de Institutos Nacionales de Salud y Hospitales de Alta Especialidad https://orcid.org/0000-0001-7295-8240

Gonzalo Salgado-Montes de Oca

Centro de Investigacion en Enfermedades Infecciosas - INER https://orcid.org/0000-0002-5735-8607

Santiago Avila-Rios

Centro de Investigacion en Enfermedades Infecciosas - INER https://orcid.org/0000-0003-3371-4248 Juan Carlos Lopez-Alvarenga 
University of Texas Rio Grande Valley https://orcid.org/0000-0002-0966-8766

Srinivas Mummidi

University of Texas Rio Grande Valley https://orcid.org/0000-0002-4068-6380

Joselin Hernandez-Ruiz ( $\sim$ hernandezjoselin@hotmail.com )

Hospital General de México "Dr. Eduardo Liceaga" https://orcid.org/0000-0002-0571-2563

\section{Method Article}

Keywords: COVID-19, Maraviroc, CCR5, Favipiravir, RdRP

Posted Date: September 10th, 2021

DOI: https://doi.org/10.21203/rs.3.rs-107427/v4

License: (9) This work is licensed under a Creative Commons Attribution 4.0 International License. Read Full License 


\section{Abstract}

Multiple studies have established that hyperinflammatory response induced by SARS CoV-2 is a main cause of complications and death in infected subjects. Such dysfunctional immune response has been described as a dysregulated and exacerbated production of cytokines and chemokines that attracts and activates inflammatory cells, which start and sustain pulmonary and systemic damage, thus causing complications that lead to multi organ failure and death. Therefore, we suggest that blocking key inflammation receptors could help to reduce migration and activation of T cells, monocytes/macrophages and neutrophils, thus mitigating the cytokine dysregulation and averting severe complications and death. Importantly, the optimum treatment for COVID-19 severe patients should combine a modulator of the immune response plus a direct antiviral drug against SARS-CoV-2, in order to address both the hyperinflammatory effects of the immune dysregulation and the viral load. Methods: Maraviroc (MVC), a CCR5 antagonist, and Favipiravir (FPV), an antiviral, will be evaluated single and combined, added to the treatment currently used at the Hospital General de México Dr. Eduardo Liceaga for severe COVID-19 patients. One hundred patients will be allocated in four arms [Current treatment only (CT), CT+MVC, CT+FPV, CT+MVC+FPV]. Percentage of patients free of mechanical ventilation or death at day 28 , immunophenotyping and viral load will be compared between groups. Discussion: New immune focused therapies are targeting strong inflammation mediators such as IL- 6 and IL 1- $\beta$; nevertheless, to our best knowledge, only one study explores chemotaxis control. The use of a drug therapy that addresses both the regulation of the immune response and the inhibition of viral replication could at the same time, help to alleviate the hyperinflammatory condition and reduce the time of the viral clearance process, therefore improving treatment outcomes.

\section{Introduction}

The COVID-19 (Coronavirus Disease 2019) pandemic caused by infection of SARS-CoV-2 (Severe Acute Respiratory Syndrome Coronavirus 2) has caused a global mortality surrounding $3 \%$ (1). Multiple studies have found that the hyperinflammatory response induced by SARS-CoV-2 is one of the main causes of severity and death. In severe COVID-19 patients, an association was found between pneumonitis and/or ARDS (Acute Respiratory Distress Syndrome), high serum levels of proinflammatory cytokines, extensive lung damage and microthrombosis (2). The late stage of the disease is difficult to manage and many patients die $(3,4)$. Based on the reports of the Chinese Disease Control Center, Cascella and cols. (5) classified the patients according to clinical severity in three groups (Table 1).

It has been proposed that the critical course of the disease is caused by an exacerbated and poorly understood immune response, linked to the phenomenon known as "cytokine storm" or cytokine release syndrome (6). Albeit it is not completely clear what initiates and propagates the cytokine storm, the severity of COVID-19, combined with rapid pandemic spread, has placed unprecedented pressure on the global healthcare system, and therapeutic strategies are urgently needed. 
Pathological studies of patients lethally infected by COVID-19 had reported acute pulmonary edema, abundant infiltration of inflammatory cells, multiple organ failure, thromboembolic complications and septicemia $(7,8)$. One of the mechanisms that could precede functional and tissue damage is the infiltration of inflammatory cells, triggered by the release of chemokines $(9,10)$.

Gene studies in lung samples identified overexpression of CCL2 and CCL3 chemokines (11). Furthermore, Huang and cols. (12) reported that besides leukopenia and lymphopenia, hospitalized patients had higher plasma concentrations of CCL3 and CCL4 upon admission than healthy subjects. They also mention that SARS and MERS physiopathology is outlined by an increase of proinflammatory cytokines and chemokines in serum (IL-I $\beta$, IL-6, IL-12, IFN- $\gamma$ and CCL2). Previously, serum CXCL10 and CCL7 were identified as predictors of progression (13). Hence, it is of notice that the cytokine storm is accompanied by chemokine-induced migration of white cells, particularly CCL2, CCL3, CCL7 and CXCL10.

CCR5 is a G-protein-coupled chemokine receptor expressed by dendritic cells, monocytes, macrophages, natural killer (NK) cells, Th1 cells, Th17 cells and Treg cells which has multiple ligands, namely CCL3, CCL4, CCL5, CCL7 and CCL8 (14).

In respiratory diseases, it has been shown that CCR5 is involved in neutrophil recruitment to the lungs (15). In that sense, in human subjects with chronic pulmonary inflammatory diseases, infiltrated neutrophils overexpress CCR5, induced by activation of TLRs and NOD2 (16). Neutrophils' infiltration in pulmonary capillaries, alveolar extravasation and neutrophilic mucositis have already been observed in COVID-19. (17). Despite the precise mechanism that drives such infiltration remains unknown, it is feasible that CCR5 may play a critical role in the immunopathology of COVID-19 (18).

Along with phagocytosis and oxidative burst, neutrophils have another resource to eliminate pathogens: NETosis, a distinct form of programmed, necrotic cell death characterized by the neutrophilic release of network organized protein and DNA structures known as "neutrophil extracellular traps" (NETs), which are able to capture and entangle such pathogens (19). Though beneficial against pathogens, NETs could stimulate certain disease processes (20). Excessive formation of NETs could trigger a chain of inflammatory reactions that destroys surrounding tissue and facilitates micro thrombosis (21). Previous reports associate aberrant formation of NETs to pulmonary disorders, namely ARDS (22). The increase in D dimer described as a severity marker in COVID-19 severe patients, could be related to NETosis, since it 
has an essential role in the start and progression of thrombosis in veins and arteries (23). Hence, all these neutrophil functions could be part of both the tissue damage and microthrombosis in COVID-19.

As previously mentioned, the chemokines increased in COVID-19 severe patients are CCL3, CCL 5 and CCL7. All these are CCR5 ligands; thus, our group hypothesizes that a CCR5 blockade could prevent leukocyte migration to the lung and attenuate the cytokine storm, and can be considered a therapeutic target (24). Moreover, a monoclonal antibody targeted against CCR5 (Leronlimab, also known as PR0140) was able to restore lymphocyte levels and decrease IL-6 in 10 COVID-19 patients (18).

One of these drugs is Maraviroc (MVC) (25), an oral CCR5 antagonist, mainly used as an anti-retro viral that impedes binding of the gp120 protein to CCR5, thus avoiding viral internalization. (26). MVC has not been widely studied in the context of reduction of hyperinflammatory conditions. However, some reports have found interesting effects in modulation or resolving of general inflammatory conditions, such as reduction of cytokine expression by in vitro human adipocytes (27), and as an alleviating agent of hemorrhage-induced hepatic injury in rats by a PPAR-y depending pathway (28). Furthermore, it was used in a phase II study to minimize the graft $v s$. host disease in bone marrow stem cell transplant in pediatric patients (29). It has also been observed that MVC decreases mucosal inflammation (30), VCAM-1 (31), T cell infiltration, neuroinflammation (32) and endothelial dysfunction (33). Regarding the lung, a model of induced hemorrhagic shock in rats reported that MVC has a protective role against pulmonary damage (34). All the aforementioned, along with the broad safety range of MVC, good tolerance an low incidence of adverse effects (35) makes it an excellent candidate to be used as a modulator of the dysregulated immune response in COVID-19.

On the other hand, in silico studies $(36,37)$, aimed to find possible candidates for the treatment of SARSCoV-2, and found that MVC could have a direct antiviral activity by binding to the main protease of the virus (Mpro). Other in silico studies propose that MVC could have an antiviral effect based on structural similarity to inhibitors of viral proteins (38), and on its binding capacity to the hinge site receptor binding motif (RBM), and fusion peptide (FP) (39). Moreover, there is also a report of MVC inhibiting SARS-CoV2 multiplication in cell culture (40). Altogether, this body of evidence suggests that MVC could not only block the CCR5-dependent migration to the lung, but also reduce the viral load.

We hypothesized that an effective treatment for COVID-19 severe patients should combine a modulator of the immune response with a direct antiviral drug against SARS-CoV-2, in order to address both the hyperinflammatory effects of the immune dysregulation and the viral load, thus yielding best results. 
Favipiravir (FPV), directly inhibits viral replication and transcription by selective inhibition of the viral enzyme RNA-dependent RNA polymerase (RdRP) (41-44).

FPV has been used successfully against A H1N1 influenza $(45,46)$. Regarding COVID-19, an open randomized study in 80 mild patients found that FPV reduced the time of viral clearance by $50 \%$ compared to Lopinavir/Ritonavir with less adverse effects (47). Another open randomized study in moderate patients reported FPV to be more effective in clinical recovery compared to Arbidol (48). An in vitro study found that FPV is capable to suppress the SARS-CoV-2 infection at high concentrations (49). A clinical study combining FPV with methylprednisolone for severe COVID-19 pneumonia reported good results (50). Finally, to date there are more than 30 studies registered in the U.S. National Library of Medicine (ClinicalTrails.gov) that evaluate FPV and 4 studies (including this) with MVC in COVID-19 patients, which are the following:

a. A multicenter study in two hospitals in Madrid and Barcelona, Spain (NCT04441385).

b. A study in Rhode Island, USA (NCT04435522).

C. A study in Seville, Spain, (NCT04710199).

To our best knowledge, at the moment (September 2021) there is not a study that evaluates both drugs for COVID-19 in the same trial.

\section{Design And Methods}

This a proof-of-concept $(51,52)$ open label, randomized, controlled, stratified by sex trial will be carried out in hospitalized patients at the Hospital General de México "Dr. Eduardo Liceaga" (HGMEL), located at Mexico City, Mexico. The protocol has been duly registered and approved by the Institutional Committees of Research, Ethics and Biosafety (Approval number DI/20/407/04/38), and registered in the Federal Commission for Prevention of Sanitary Risks, COFEPRIS (Approval number 203300410A0290/2021)

\section{Design}

Four arms will be conducted: (Figure 1)

1. Current therapy (CT) only: The current treatment for hospitalized COVID-19 patients at the HGMEL, consisting in enoxaparin, dexamethasone, and antibiotics if associated bacteremia is present, as per 
currently used at HGMEL.

2. CT+MVC: $[\mathrm{CT}]+[300$ mg. MVC p.o. bid for 10 days $]$

3. CT+FPV: [CT] + [FPV p.o. for a 7-day period: $1600 \mathrm{mg}$ bid on day 1 and $600 \mathrm{mg}$ bid days 2-7]

4. CT+MVC+FPV: [CT] + [600 mg. MVC bid for 10 days $]+[200 \mathrm{mg}$. FPV for a 7-day period. $1600 \mathrm{mg}$ bid on day 1 and $600 \mathrm{mg}$ bid days 2-7]

\section{FIGURE 1}

\section{Eligibility criteria}

Screening: Upon admission, screening criteria will be applied in the Emergency service to select the candidates

- Adult patients (18-80)

- Within 12 days of the appearance of symptoms

- Severe non-critical clinical stage at admission

- At least one of the following risk factors: $\mathrm{DM}, \mathrm{BMI} \geq 28$, hypertension history or age $>65$

\section{Inclusion criteria}

These will confirm the selected subjects for enrollment.

- Positive for SARS-CoV-2 confirmed by PCR or rapid antigen test

- PaFi 150-300 (or SpFi equivalent)

- LDH (Lactate dehydrogenase) $>250$

- Thoracic image with $>25 \%$ pulmonary compromise infiltration, according to RALE score (2-4 points).

- Normal hepatic function, defined as a maximum of a fivefold increase of transaminases.

- Signed informed consent.

- Women in fertile capability must accept the use of a contraceptive method for 90 days after treatment completion. 
- Pregnant or lactating women

- Participating in another clinical trial

- Clinical evidence of an infectious disease different from COVID-19 at the time of admission

- Oxygen saturation $<70 \%$ (Unassisted)

- Glomerular filtration rate $<30 \mathrm{ml} / \mathrm{min} / 1.73 \mathrm{~m}^{2}$ and known history of pre-existing chronic kidney disease (Chronic kidney disease stage 4 or 5 )

- Coronary disease (acute or chronic)

- Previous history of allergies to MVC or FPV

- Autoimmune disorders

- History of any previous transplant

- Patients with polyconsumption of toxic substances (Defined as a combination of two or more addictions to tobacco, alcohol, marihuana, cocaine, etc)

- Treatment with erythromycin

- Under treatment with psychotropic drugs of any kind.

- Cancer of any kind

- On mechanically assisted ventilation at the time of randomization

\section{Elimination criteria}

- Withdrawal of the informed consent

- Patients who fail to receive two consecutive doses of the trial drugs.

\section{Endpoints}

- Primary: Progression-free survival rate (PFS) for mechanical ventilation or death [time frame: day 28]

- Secondary:

- Progression-free survival rate for mechanical ventilation or death [Time frame: day 5]

- Time of improvement in at least 2 categories in the WHO 7-category ordinal scale (53) [Time frame: day 15]

- Evaluation of the response to treatment of the hyperinflammatory condition by analysis of the change rate in percentage of lymphocytes, monocytes, and neutrophils, as well as 
proinflammatory chemokine and cytokine levels [Time frame: day 10-1]

Sample size

The calculation was performed to compare survival curves using EPIDAT 4.2, based upon the 2020 casuistry observed at the Infectology Department of the HGMEL, with a mechanical ventilation FPS rate in severe cases of $65 \%$, and an expected value of $80 \%$, with a confidence level of $80 \%$. For a 4 -arm study, the following is obtained:

Sample size and power for survival curves comparison:

Groups: $\quad 4$

Estimated losses: $\quad 15 \%$

Confidence level: $\quad 80.0 \%$

Expected FPS (\%)

Group 1: 65

Group 2: 75

Group 3: 75

Group 4: 80

Power (\%) Total

$80.0 \quad 98$ 
Therefore, 25 patients will be allocated by group: 100 total.

\section{Randomization}

Subjects will be randomized using EPIDAT v. 4.2 considering stratification by sex.

\section{Statistical analysis}

For the calculation of the efficacy, all those patients that completed the study with no major deviations from the foreseen results (improvement, progression to critical or death) will be considered as the Population per Protocol (PP). In order to avoid bias by the effect of termination of treatment due to causes different from the foreseen ones, the modified intention to treat (mITT) will be calculated, based on the criterion of at least one dose taken and at least one measurement after basal of the endpoints.

The primary endpoint (PFS for mechanical ventilation or death) [time frame: day 28] will be analyzed using a Kaplan-Meier Log Rank model to compare the 4 arms.

The secondary endpoints will be compared between arms as follows:

- PFS rate for mechanical ventilation or death [Time frame: day 5]: Kaplan-Meier Log Rank model.

- Time of improvement in at least 2 categories in the WHO 7-category ordinal scale (53) (This variable is applicable to responders only) [Time frame: day 15]: Kruskal-Wallis test.

- Change rate in expression of cytokines and chemokines in serum [Time frame: day 10-1]: One-way ANOVA will be used to compare change rate of each cytokine/chemokine. Additionally, a Principal Component Analysis (PCA) will be performed for clusters identification and their relationship with treatment response.

- Change rate in the patterns of activation, trafficking and exhaustion in peripheral blood lymphocytes, monocytes and neutrophils [Time frame: day 10-1]: Data will be analyzed for subpopulations, frequencies (\%) and mean fluorescence intensities (MFI) for each molecule and their interactions.

- By subsets: Gating using Flowing Software 
- By clusters: PCA using RStudio

Data will be controlled by confounding factors (BMI, sex, hypertension, and diabetes).

IBM SPSS version 21 and RStudio v. 3.6 .3 will be used for the statistical analysis. A confidence interval of $95 \%$ and a significance level of $p \leq 0.05$ will be considered.

\section{Procedure}

Patients eligible by screening criteria are invited to participate in the protocol. Upon acceptance, a detailed explanation is given, and signature of a written informed consent form is requested. One copy of the signed informed consent is kept in the patient's file, and one more is given to the patient.

If the confirmatory tests for inclusion criteria show that not all are met, or any exclusion criterion is found, the subject is informed and is not recruited.

Once participation is confirmed, patients are registered in the data collection sheet and undergo a general clinical and medical record assessment. Samples for blood count, blood chemistry and blood gases are collected, as well as saliva for viral load and blood for evaluation of immune status. A general approach to the study is presented in Table 2

NPE will be used to measure SARS-CoV-2. Blood samples will consist of $25 \mathrm{ml}$ : for cytokines and chemokines measurement on serum and activation and trafficking markers on leukocytes. Saliva, plasma, and leukocytes samples will be transported to the BSL3 laboratory of CIENI-INER (Research Center for Infectious Diseases at the National Respiratory Diseases Institute) for these analysis.

Participation of the subjects will end upon discharge by improvement or death. If patients progress to critical condition, tablets will be crushed and administered using a nasogastric tube. 
Even in the occurrence of anticipated discharge or death, the patient's information is kept and processed for data analysis, as long as the patient or their relatives do not retire their consent. Likewise, participation of the subjects is terminated before term if a complication or adverse effect occurs that can be related to the drug under study and is ruled so by the responsible physician. If that is the case, the necessary medical support is given to correct the adverse effect, and the patient is kept in observation.

Reporting of $A E / S A E$ is done by trial physicians on a daily basis in compliance with the current procedure of the Hospital, which demands reporting to the Pharmacovigilance, Ethics, and Biosafety Committees of the Hospital within the first 24 hours. In turn, the Pharmacovigilance Committee informs the Uppsala Monitoring Centre.

Follow up

Discharged patients are contacted by telephone on a weekly basis until day 28. Questions are addressed for symptoms and possible adverse effects.

The study will be considered finished when all the enrolled subjects calculated in the sample size complete their participation.

\section{Discussion}

In this study, we propose the use of MVC and/or FPV as a therapeutic resource to prevent or ameliorate the immune dysregulation, decrease the viral load and reduce complications and death in severe patients in risk of progressing to critical. The cells accountable for such dysregulation express receptors like CCR5, which mediate their trafficking to the lungs. Therefore, it is considered a therapeutic target.

In recent studies with other CCR5 inhibitors such as Leronlimab, a significant decrease in peripheral blood levels of CCL5, IL- 6 and IL-1 $\beta$, as well as inflammation and viral load has been observed. This could be related with a reduction of inflammation markers like ferritin, D-dimer and CRP $(54,55)$. Therefore, MVC could, as mentioned before, prevent the trafficking of pro-inflammatory leukocytes to the lungs through CCR5 blockade in a similar manner. Nevertheless, MVC has a technical advantage, because unlike Leronlimab, it is an orally administered tablet that does not require special conditions for transport, handling and administration. 
MVC is a CCR5 antagonist that could also have an antiviral effect, albeit it has not been evaluated in the context of COVID-19. Alongside, the results could be potentiated by the direct effect of an antiviral such as FPV. It has been reported that FPV decreases the viral load by day 4-7 (47), which leads us to think that an early intervention would bring better results for the arms where FPV is going to be evaluated . Moreover, it has been observed that there exists a relationship between viral load and severity (56).

Despite newly developed SARS-CoV-2 vaccines are being massively applied, current evidence suggests that COVID-19 is a disease that will coexist with mankind for a very long period of time. Moreover, pharmacologic strategies used for treatment have not proven completely effective.

Thence, more studies of different therapeutic targets are needed to search for resources that help to improve the patients' prognosis. The use of a drug therapy that addresses both the regulation of the immune response and the inhibition of viral replication could at the same time, help to alleviate the hyperinflammatory condition and reduce the time of the viral clearance process. This study is intended to compare the therapy currently used at Hospital General de Mexico "Dr. Eduardo Liceaga" to treat COVID19 on severe non-critical patients, which does not comprise either an inflammation modulator or an antiviral, to a strategic therapy focused on the aforementioned mechanisms of pathogenicity.

\section{Limitations}

1) Viral strains were not considered. 2) MVC is an expensive drug. 3) Albeit the sample size calculation was focused on reliable parameters and therefore is solid, the sample size is limited for a better understanding of the interaction of other variables such as clinical improvement and days of hospital stay. Hence, a greater number of subjects is desirable for further studies. 4) Open studies can be potentially affected by the effect of multiple biases (e.g. placebo effect)

\section{Trial Status}

At the time of submission of this paper (September 2021), 9 patients had been recruited. The Institutional Committees of Research, Ethics and Biosafety of the HGMEL approved the protocol on June 24, 2020 (registration number DI/20/407/04/38). Registered in NIH's Clinical Trials (https://clinicaltrials.gov) on July 17 2020, COMVIVIR NCT 04475991. Recruitment is estimated to be completed by February 2022 


\section{Declarations}

\section{Funding}

This research received no specific grant from any funding agency in the public, commercial, or not-forprofit sectors.

\section{Declaration of conflicting interests}

The authors declare that there is no conflict of interest.

\section{References}

1. World Health Organization. WHO coronavirus disease (COVID-19) dashboard. [Internet]. 2020. Available from: https://covid19.who.int/

2. Merad M, Martin JC. Pathological inflammation in patients with COVID-19: a key role for monocytes and macrophages. Nat Rev Immunol. 2020 Jun 6;20(6):355-62.

3. Wang D, Hu B, Hu C, Zhu F, Liu X, Zhang J, et al. Clinical Characteristics of 138 Hospitalized Patients With 2019 Novel Coronavirus-Infected Pneumonia in Wuhan, China. JAMA. 2020 Mar 17;323(11):1061.

4. Zheng M, Gao Y, Wang G, Song G, Liu S, Sun D, et al. Functional exhaustion of antiviral lymphocytes in COVID-19 patients. Cell Mol Immunol. 2020 May 19;17(5):533-5.

5. Cascella M, Ranjik M, Cuomo A, Dublebohn SC, Di Napoli R. Features, Evaluation and Treatment Coronavirus (COVID-19) [Internet]. StatPearls [Internet]. Treasure Island, FL: StatPearls Publishing; 2020. Available from: https://www.ncbi.nlm.nih.gov/books/NBK554776/

6. Mehta P, McAuley DF, Brown M, Sanchez E, Tattersall RS, Manson JJ. COVID-19: consider cytokine storm syndromes and immunosuppression. Lancet. 2020 Mar;395(10229):1033-4.

7. Kong SL, Chui P, Lim B, Salto-Tellez M. Elucidating the molecular physiopathology of acute respiratory distress syndrome in severe acute respiratory syndrome patients. Virus Res. 2009 Nov;145(2):260-9.

8. Channappanavar R, Zhao J, Perlman S. T cell-mediated immune response to respiratory coronaviruses. Immunol Res. 2014 Aug 21;59(1-3):118-28. 
9. Qi B, Fang Q, Liu S, Hou W, Li J, Huang Y, et al. Advances of CCR5 antagonists: From small molecules to macromolecules. Eur J Med Chem. 2020;208:112819.

10. Vangelista L, Vento S. The expanding therapeutic perspective of CCR5 blockade. Front Immunol. 2018;8(JAN):1-7.

11. Yuki K, Fujiogi M, Koutsogiannaki S. COVID-19 pathophysiology: A review. Clin Immunol. 2020 Jun;215:108427.

12. Huang C, Wang Y, Li X, Ren L, Zhao J, Hu Y, et al. Clinical features of patients infected with 2019 novel coronavirus in Wuhan, China. Lancet. 2020 Feb;395(10223):497-506.

13. Liao M, Liu Y, Yuan J, Wen Y, Xu G, Zhao J, et al. Single-cell landscape of bronchoalveolar immune cells in patients with COVID-19. Nat Med. 2020 May 12;

14. Rautenbach A, Williams AA. Metabolomics as an Approach to Characterise the Contrasting Roles of CCR5 in the Presence and Absence of Disease. Int J Mol Sci. 2020 Feb 21;21(4):1472.

15. Grommes J, Drechsler M, Soehnlein O. CCR5 and FPR1 mediate neutrophil recruitment in endotoxininduced lung injury. J Innate Immun. 2014;6(1):111-6.

16. Hartl D, Krauss-Etschmann S, Koller B, Hordijk PL, Kuijpers TW, Hoffmann F, et al. Infiltrated Neutrophils Acquire Novel Chemokine Receptor Expression and Chemokine Responsiveness in Chronic Inflammatory Lung Diseases. J Immunol. 2008;181(11):8053-67.

17. Barnes BJ, Adrover JM, Baxter-Stoltzfus A, Borczuk A, Cools-Lartigue J, Crawford JM, et al. Targeting potential drivers of COVID-19: Neutrophil extracellular traps. J Exp Med. 2020;217(6):1-7.

18. Patterson BK, Seethamraju H, Dhody K, Corley MJ, Kazempour K, Lalezari JP, et al. Disruption of the CCL5/RANTES-CCR5 Pathway Restores Immune Homeostasis and Reduces Plasma Viral Load in Critical COVID-19. medRxiv. 2020;2020.05.02.20084673.

19. Brinkmann V. Neutrophil Extracellular Traps Kill Bacteria. Science (80- ). 2004 Mar 5;303(5663):1532-5.

20. Schönrich G, Raftery MJ. Neutrophil Extracellular Traps Go Viral. Front Immunol. 2016;7:366.

21. Jorch SK, Kubes P. An emerging role for neutrophil extracellular traps in noninfectious disease. Nat Med. 2017;23(3):279-87.

22. Caudrillier A, Kessenbrock K, Gilliss BM, Nguyen JX, Marques MB, Monestier M, et al. Platelets induce neutrophil extracellular traps in transfusion-related acute lung injury. J Clin Invest. $2012 \mathrm{Jul}$ 2;122(7):2661-71. 
23. Fuchs TA, Brill A, Wagner DD. Neutrophil Extracellular Trap (NET) Impact on Deep Vein Thrombosis. Arterioscler Thromb Vasc Biol. 2012 Aug;32(8):1777-83.

24. Sorbera L, Graul A, Dulsat C. Taking aim at a fast-moving target: targets to watch for SARS-CoV-2 and COVID-19. Drugs Future. 2020;45(4):1-6.

25. Fantuzzi L, Tagliamonte M, Cristina M, Lucia G. Dual CCR5 / CCR2 targeting: opportunities for the cure of complex disorders. Cell Mol Life Sci. 2019;76(24):4869-86.

26. Dorr P, Westby M, Dobbs S, Griffin P, Irvine B, Macartney M, et al. Maraviroc ( UK-427, 857 ), a Potent , Orally Bioavailable, and Selective Small-Molecule Inhibitor of Chemokine Receptor CCR5 with BroadSpectrum Anti-Human Immunodeficiency Virus Type 1 Activity. Antimicrob Agents Chemother. 2005;49(11):4721-32.

27. Díaz-Delfín J, Domingo P, Giralt M, Villarroya F. Maraviroc reduces cytokine expression and secretion in human adipose cells without altering adipogenic differentiation. Cytokine. 2013;61(3):80815.

28. Liu F-C, Tsai Y-F, Yu H-P. Maraviroc Attenuates Trauma-Hemorrhage-Induced Hepatic Injury through PPAR Gamma-Dependent Pathway in Rats. Mohanraj R, editor. PLoS One. 2013 Oct 18;8(10):e78861.

29. Khandelwal P, Fukuda T, Teusink-Cross A, Kashuba ADM, Lane A, Mehta PA, et al. CCR5 inhibitor as novel acute graft versus host disease prophylaxis in children and young adults undergoing allogeneic stem cell transplant: results of the phase II study. Bone Marrow Transplant. 2020 Apr 9;

30. Mencarelli A, Cipriani S, Francisci D, Santucci L, Baldelli F, Distrutti E, et al. Highly specific blockade of CCR5 inhibits leukocyte trafficking and reduces mucosal inflammation in murine colitis. Sci Rep. 2016 Nov 5;6(1):30802.

31. Francisci D, Falcinelli E, Baroncelli S, Petito E, Cecchini E, Weimer LE, et al. Potential antiinflammatory effects of maraviroc in HIV-positive patients: A pilot study of inflammation, endothelial dysfunction, and coagulation markers. Scand J Infect Dis. 2014;46(6):466-70.

32. Mondal S, Rangasamy SB, Roy A, Dasarathy S, Kordower JH, Pahan K. Low-Dose Maraviroc, an Antiretroviral Drug, Attenuates the Infiltration of T Cells into the Central Nervous System and Protects the Nigrostriatum in Hemiparkinsonian Monkeys. J Immunol. 2019;202(12):3412-22.

33. Francisci D, Pirro M, Schiaroli E, Mannarino MR, Cipriani S, Bianconi V, et al. Maraviroc Intensification Modulates Atherosclerotic Progression in HIV-Suppressed Patients at High Cardiovascular Risk. A Randomized, Crossover Pilot Study. Open Forum Infect Dis. 2019 Apr 1;6(4):1-7.

34. Liu F-C, Zheng C-W, Yu H-P. Maraviroc-Mediated Lung Protection following Trauma-Hemorrhagic Shock. Biomed Res Int. 2016;2016:1-8. 
35. Abel S, Van Der Ryst E, Rosario MC, Ridgway CE, Medhurst CG, Taylor-Worth RJ, et al. Assessment of the pharmacokinetics, safety and tolerability of maraviroc, a novel CCR5 antagonist, in healthy volunteers. Br J Clin Pharmacol. 2008;65(SUPPL. 1):5-18.

36. Shamsi A, Mohammad T, Anwar S, Alajmi M, Hussain A, Rehman MT, et al. Glecaprevir and Maraviroc are high-affinity inhibitors of SARS-CoV-2 main protease: Possible therapeutic implication in COVID-19. Biosci Rep. 2020 May 22;

37. Mohammad T, Shamsi A, Anwar S, Umair M, Hussain A, Rehman MT, et al. Identification of highaffinity inhibitors of SARS-CoV-2 main protease: Towards the development of effective COVID-19 therapy. Virus Res. 2020;288(June):198102.

38. Tazikeh-Lemeski E, Moradi S, Raoufi R, Shahlaei M, Janlou MAM, Zolghadri S. Targeting SARSCOV-2 non-structural protein 16: a virtual drug repurposing study. J Biomol Struct Dyn. 2020 Jun 23;114.

39. Ramírez-Salinas GL, Martínez-Archundia M, Correa-Basurto J, García-Machorro J. Repositioning of Ligands That Target the Spike Glycoprotein as Potential Drugs for SARS-CoV-2 in an In Silico Study. Molecules. 2020 Nov 29;25(23):5615.

40. Risner KH, Tieu K V, Wang Y, Bakovic A, Alem F, Bhalla N, et al. Maraviroc inhibits SARS-CoV-2 multiplication and s-protein mediated cell fusion in cell culture. bioRxiv. 2020;2020.08.12.246389.

41. Venkatasubbaiah M, Dwarakanadha Reddy P, Satyanarayana S V. Literature-based review of the drugs used for the treatment of COVID-19. Curr Med Res Pract. 2020 May;10(3):100-9.

42. Furuta Y, Gowen BB, Takahashi K, Shiraki K, Smee DF, Barnard DL. Favipiravir (T-705), a novel viral RNA polymerase inhibitor. Antiviral Res. 2013;100(2):446-54.

43. Janissen R, Woodman A, Lee K, Moustafa I, Huang P, Kuijpers L, et al. Induced copy-back RNA synthesis as a novel therapeutic mechanism against RNA viruses. bioRxiv. 2020;1-24.

44. Shaevitz JW, Abbondanzieri EA, Landick R, Block SM. Backtracking by single RNA polymerase molecules observed at near-base-pair resolution. Nature. 2003 Dec 23;426(6967):684-7.

45. Bank C, Renzette N, Liu P, Matuszewski S, Shim H, Foll M, et al. An experimental evaluation of druginduced mutational meltdown as an antiviral treatment strategy. Evolution (N Y). 2016;70(11):2470-84.

46. Jensen JD, Lynch M. Considering mutational meltdown as a potential SARS-CoV-2 treatment strategy. Heredity (Edinb). 2020;124(5):619-20.

47. Cai Q, Yang M, Liu D, Chen J, Shu D, Xia J, et al. Experimental Treatment with Favipiravir for COVID19: An Open-Label Control Study. Engineering. 2020 Oct;6(10):1192-8. 
48. Chen C, Huang J, Cheng Z, Wu J, Chen S, Zhang Y, et al. Favipiravir versus Arbidol for COVID-19: A Randomized Clinical Trial. medRxiv. 2020;1-30.

49. Wang $M$, Cao R, Zhang L, Yang X, Liu J, Xu M, et al. Remdesivir and chloroquine effectively inhibit the recently emerged novel coronavirus (2019-nCoV) in vitro. Cell Res. 2020;30(3):269-71.

50. Murohashi K, Hagiwara E, Kitayama T, Yamaya T, Higa K, Sato Y, et al. Outcome of early-stage combination treatment with favipiravir and methylprednisolone for severe COVID-19 pneumonia: A report of 11 cases. Respir Investig. 2020;58(6):430-4.

51. Cartwright ME, Cohen S, Fleishaker JC, Madani S, McLeod JF, Musser B, et al. Proof of concept: A PhRMA position paper with recommendations for best practice. Clin Pharmacol Ther. 2010;87(3):27885.

52. Quan H, Chen X, Lan Y, Luo X, Kubiak R, Bonnet N, et al. Applications of Bayesian analysis to proofof-concept trial planning and decision making. Pharm Stat. 2020;19(4):468-81.

53. World Health Organization. Novel Coronavirus COVID-19 Therapeutic Trial Symptoms. WHO R\&D Blueprint. 2020.

54. Patterson BK, Seethamraju H, Dhody K, Corley MJ, Kazempour K, Lalezari J, et al. CCR5 inhibition in critical COVID-19 patients decreases inflammatory cytokines, increases CD8 T-cells, and decreases SARSCoV2 RNA in plasma by day 14. Int J Infect Dis. 2021 Feb;103:25-32.

55. Yang B, Fulcher JA, Ahn J, Berro M, Goodman-Meza D, Dhody K, et al. Clinical Characteristics and Outcomes of Coronavirus Disease 2019 Patients Who Received Compassionate-Use Leronlimab. Clin Infect Dis. 2020 Oct 20;1-8.

56. Argyropoulos K V., Serrano A, Hu J, Black M, Feng X, Shen G, et al. Association of Initial Viral Load in Severe Acute Respiratory Syndrome Coronavirus 2 (SARS-CoV-2) Patients with Outcome and Symptoms. Am J Pathol. 2020;190(9):1881-7.

\section{Tables}

Table 1: Classification of COVID patients according to Cascella and cols. StatPearls [Internet]. Treasure Island, FL: StatPearls Publishing; 2020. Available from: https://www.ncbi.nlm.nih.gov/books/NBK554776/ 


\begin{tabular}{|l|l|c|}
\hline & Feature & $\%$ \\
\hline $\begin{array}{l}\text { Mild } \\
\text { Disease }\end{array}$ & Mild or absent pneumonia & 81 \\
\hline $\begin{array}{l}\text { Severe } \\
\text { Disease }\end{array}$ & $\begin{array}{l}\text { Dyspnea, } \\
\text { Respiratory rate } \geq 30 / \mathrm{min}_{1} \\
\text { Oxygen saturation }\left(\mathrm{SpO}_{2}\right) \leq 93 \%, \\
\text { Kirby index (ratio between partial oxygen pressure, } \mathrm{PaO}_{2} \text { and oxygen } \\
\text { fraction inspired, } \mathrm{FiO} 2)<300, \\
\text { Pulmonary infiltrate in thorax imaging }>50 \% .\end{array}$ & 14 \\
\hline $\begin{array}{l}\text { Critical } \\
\text { Disease }\end{array}$ & $\begin{array}{l}\text { Respiratory failure } \\
\text { Septic shock } \\
\text { Multiple organ failure. }\end{array}$ & 5 \\
\hline
\end{tabular}

Table 2. Overview of the study, including time frames, eligibility, allocation of subjects and sampling 


\begin{tabular}{|c|c|c|c|c|c|c|c|c|c|c|c|c|c|c|c|}
\hline \multicolumn{16}{|c|}{ STUDY PERIOD } \\
\hline & Enrollment & Allocation & \multicolumn{13}{|c|}{ Post-allocation } \\
\hline & Screening & & \multicolumn{10}{|c|}{ Treatment period } & \multicolumn{2}{|c|}{$\begin{array}{l}\text { Follow-up } \\
\text { period }\end{array}$} & \multirow{2}{*}{$\begin{array}{l}\text { Close } \\
\text { out } \\
\text { D180 }\end{array}$} \\
\hline EVENT & $-\mathrm{D} 2$ & D0 & D1 & D2 & D3 & D4 & D5 & D6 & D7 & D8 & D9 & D10 & D15 & D28 & \\
\hline Informed consent & $\mathrm{X}$ & & & & & & & & & & & & & & \\
\hline Screening criteria & $\mathrm{X}$ & & & & & & & & & & & & & & \\
\hline Inclusion criteria & $\mathrm{X}$ & & & & & & & & & & & & & & \\
\hline Allocation & & $\mathrm{X}$ & & & & & & & & & & & & & \\
\hline \multicolumn{16}{|l|}{ INTERVENTION } \\
\hline $\begin{array}{l}\text { Arm A: Current } \\
\text { Therapy (CT) }\end{array}$ & & & $\mathrm{X}$ & $\mathrm{X}$ & $\mathrm{X}$ & $\mathrm{X}$ & $\mathrm{X}$ & $\mathrm{X}$ & $\mathrm{X}$ & $\mathrm{X}$ & $\mathrm{X}$ & $\mathrm{X}$ & & & \\
\hline Arm B: MVC + CT & & & $\mathrm{X}$ & $\mathrm{X}$ & $\mathrm{X}$ & $\mathrm{X}$ & $\mathrm{X}$ & $\mathrm{X}$ & $\mathrm{X}$ & $\mathrm{X}$ & $\mathrm{X}$ & $\mathrm{X}$ & & & \\
\hline Arm C: FVP + CT & & & $\mathrm{X}$ & $\mathrm{X}$ & $\mathrm{X}$ & $\mathrm{X}$ & $\mathrm{X}$ & $\mathrm{X}$ & $\mathrm{X}$ & $\mathrm{X}$ & $\mathrm{X}$ & $\mathrm{X}$ & & & \\
\hline $\begin{array}{l}\text { Arm D: MVC + FVP } \\
+ \text { CT }\end{array}$ & & & $\mathrm{X}$ & $\mathrm{X}$ & $\mathrm{X}$ & $\mathrm{X}$ & $\mathrm{X}$ & $\mathrm{X}$ & $\mathrm{X}$ & $\mathrm{X}$ & $\mathrm{X}$ & $\mathrm{X}$ & & & \\
\hline \multicolumn{16}{|l|}{ ASSESSMENTS } \\
\hline \multicolumn{16}{|l|}{ Variables } \\
\hline Hematic biometry & $\mathrm{X}$ & & & & & & & & & & & & & & \\
\hline Electrocardiogram & & $\mathrm{X}$ & & & & & & & & & & $\mathrm{X}$ & & & \\
\hline Viral Load & & $\mathrm{X}$ & & & $\mathrm{X}$ & & & & $\mathrm{X}$ & & & $\mathrm{X}$ & & & \\
\hline Chemokines & & $\mathrm{X}$ & & & & & & & & & & $\mathrm{X}$ & & & \\
\hline Cytokines & & $\mathrm{X}$ & & & & & & & & & & $\mathrm{X}$ & & & $\mathrm{X}$ \\
\hline Chest x-ray & $\mathrm{X}$ & & & & & & & & & & & $\mathrm{X}$ & & & \\
\hline Disease progress & & & & & & & $\mathrm{X}$ & & & & & & & $\mathrm{X}$ & \\
\hline $\begin{array}{l}\text { Days free of } \\
\text { mechanical } \\
\text { ventilation }\end{array}$ & & & & & & & $\mathrm{X}$ & & & & & & $\mathrm{X}$ & $\mathrm{X}$ & \\
\hline
\end{tabular}

\section{Figures}




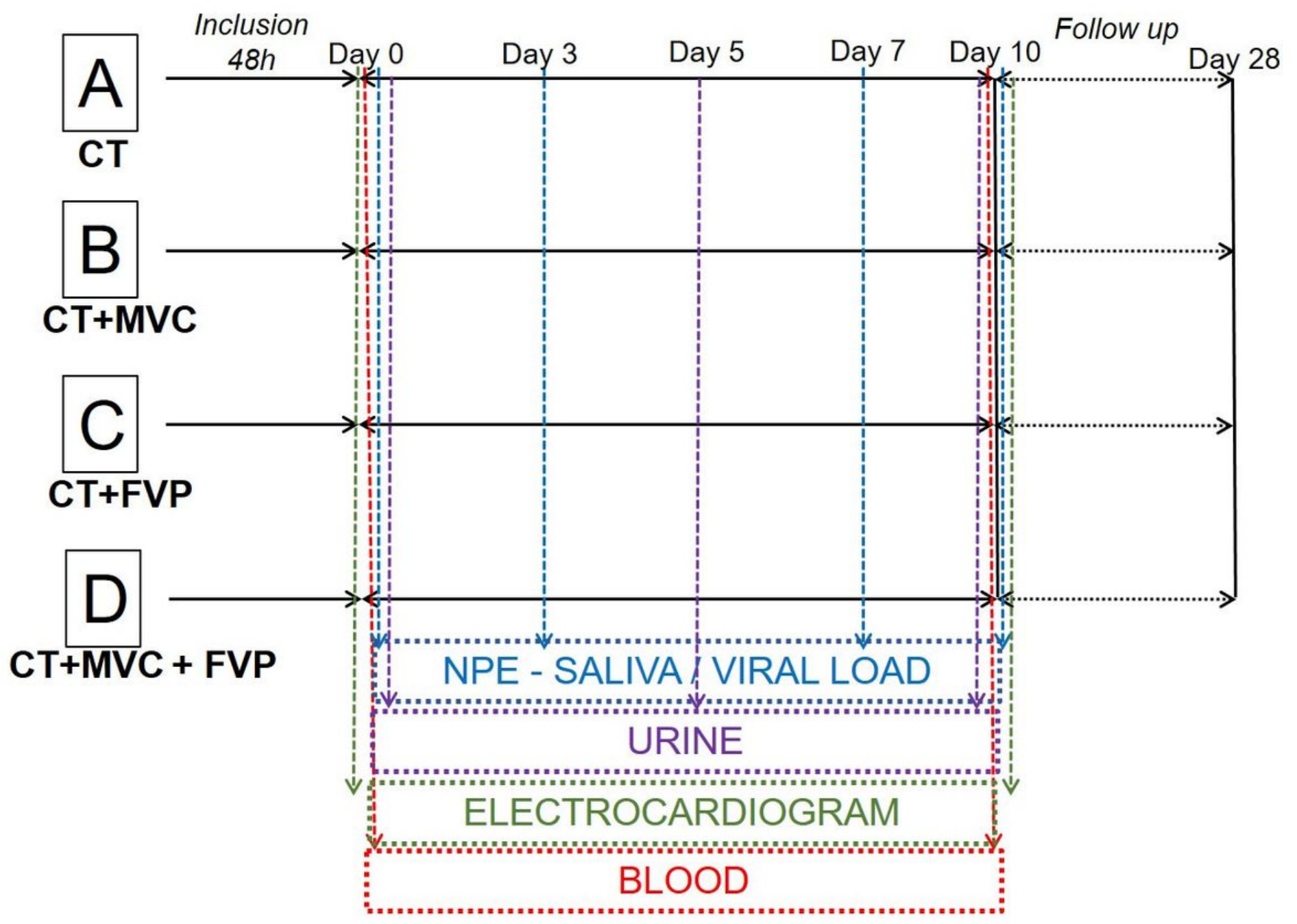

Figure 1

Overall design of the study and description of the arms, main events and sampling days. CT: Currently used treatment. MVC: Maraviroc. FPV: Favipiravir. NPE: Nasopharyngeal exudate 